\title{
Anomalous Superior Thyroid Artery
}

\author{
Vandana Mehta ${ }^{1}$, Rajesh.K.Suri ${ }^{2}$, Jyoti Arora ${ }^{3}$, Gayatri Rath ${ }^{4}$, Srijit Das ${ }^{5}$
}

\author{
${ }^{1-4}$ Department of Anatomy, Vardhaman \\ Mahavir Medical College and Safdarjung \\ Hospital, Ansari Nagar, New Delhi-110029, \\ India \\ ${ }^{5}$ Department of Anatomy, National University \\ of Malaysia, 50300 Kuala Lumpur, Malaysia
}

\section{Corresponding Author}

Dr Vandana Mehta

Department of Anatomy,

Vardhaman Mahavir Medical College and Safdarjung Hospital,

New Delhi, India

Email.drvandanamehta@gmail.com

\begin{abstract}
The variations in the pattern of distribution of superior thyroid artery assume paramount importance for neck surgeons, in view of its vital topographical relationship to the external laryngeal nerve. In this study, we report an unusual variation in the arterial supply of the thyroid gland, which was detected during a routine dissection of an adult male cadaver. The right superior thyroid artery was absent whereas the left superior thyroid artery took origin from the left common carotid artery and showed a dominant pattern of distribution supplying the superior aspect of both the left and right lobes of the thyroid gland. It exhibited a usual relationship with the left external laryngeal nerve. The inferior thyroid arteries did not show any unusual distribution. Knowledge of such arterial variations related to the thyroid gland is immensely helpful for surgeons in order to put ligature on anomalous artery and to avoid damage to vital structures in this area, such as the external laryngeal nerve.
\end{abstract}

\section{Key Words}

thyroid gland, anatomy, superior thyroid artery, variation, surgery.

\section{INTRODUCTION}

Variations in the thyroid vasculature are frequently documented in classical anatomical, surgical and radiological textbooks. ${ }^{1,2,3}$ The superior thyroid artery normallytakesitsoriginsfromtheexternalcarotidartery. Paststudieshavereportedtheincidenceoforiginofthe superiorthyroidarteryfromthecommoncarotidarteryin $5-45 \%$ cases. $^{4}$

Identification of anatomic variations including arterial variations related to the thyroid gland is of immense importanceinformulatingplannedsurgicalapproaches tothethyroidglandandinalertingthesurgeonstoavert inadvertent injuries to the vital anatomical structures inthisarea.Additionally, adetailedknowledgeofthese explicit arterial variations is extremely helpful while carryingoutprocedureslikecarotidangiographies, neck dissections and thyroid resections. ${ }^{5}$ The implications of such variations of superior thyroid arteries may be important for academic and clinical purposes.

\section{CASE REPORT}

During theroutineneckdissection ofa 45yearoldmale cadaver at the Department of Anatomy, Vardhaman MahavirMedicalCollege, NewDelhi, therightsuperior thyroidarterywasfound tobeabsent.Interestingly, the leftsuperior thyroidartery wasfound to originatefrom the left common carotid artery instead of left external carotid artery (Figure 1.). Additionally, it presented a remarkabledistributionbyforminganinverted'Y'shaped loopthatsplayedoverthesuperiorpolesofboththelobes ofthethyroidglandthussupplying thesuperioraspect of right lobe also. The stem of the' $Y$ ' arose $0.5 \mathrm{~cm}$ distal tobifurcation oftheleftcommoncarotidartery (marked with an asterixin Figure 1.) into its external and internal branchesandthetwolimbsofthe' $Y$ 'suppliedthesuperior aspectofthetwolobes.Theleftexternallaryngealnerve displayeditsusual relationshipwithleftsuperiorthyroid artery.However,theright-sidednervewasunremarkable. Theinferiorthyroidarteriesexhibitednormalmorphology. 


\section{DISCUSSION}

Thearterialsupplytothehumanthyroidglandconsistsof pairedsuperiorandinferiorthyroidarteriesascompared tothemammalsandreptilesthathavesolitarysuperior andinferiorarteriesrespectively. ${ }^{6}$ Thelowestincidence arterialanomaliesofthethyroidglandhavebeenrecorded intheSwisspopulation withthehighestintheAmericans.

${ }^{7,8}$ However, there is paucity of literature with regard to anomalous superior thyroid arteries in the Asian subcontinent especially in India.

A case of low origin of right superior thyroid artery was reportedearlierwheretheleftsidedvesselwasundeveloped . ${ }^{4}$ Strikingly, the presentcaseappearsto beuniquewith respecttotheabsenceoftherightsuperiorthyroidartery andanapparentdominanceoftheleftsuperiorthyroid artery.Thereisagreater propensity for the low origin of superior thyroid artery to occur in females and on the leftside. ${ }^{4}$ However, theobservationsinourcasearenot inaccordancewith thesefindings. Thereisadefiniteand clearproximalshifting oftheorigin ofthesuperiorthyroid arteryinJapanesesubjects ${ }^{4}$ butsuchfindingsareyettobe quantified in Indian subjects.

Apaststudyrevealedtheabsenceoftheleftsidedsuperior and inferior thyroid arteries. ${ }^{9}$ In this case, the thyroidea ima arteryoriginating from the internal thoracicartery suppliedthethyroidgland.Anontogenicexplanationfor theanomalyinthepresentcasecouldbethepersistence oftheoriginalretiformvascularsysteminconnectionwith thecommoncarotidarteries. ${ }^{10,11}$ Thesepersistingchannels supplement or substitute the regular arteries, thereby ensuringanampleandsufficientbloodsupplytothatside of thyroid gland, which is devoid of regular vessels.

Itseemsreasonabletoproposethatasurgicalapproach forthyroidresectionorcarotidsheathdissectionshould beexercisedwithextremecautioninthepresenceofsuch arterial variations.

Additionally, the surgeons should perform operative manoeuvre commencing the approach to the thyroid gland $3 \mathrm{~cm}$ proximaltothecommoncarotidbifurcation, identifying superior belly of omohyoid as a reliable landmark. ${ }^{4}$

Inlieu oftheabsentsuperiorandinferiorthyroidarteries, thethyroideaimaarterywasofremarkablediameterand proved to be a major source of the blood supply to the thyroidgland. However,ourstudyrevealedtheabsence oftherightsuperiorthyroidarterywithremarkableand uniquedominanceoftheleftsuperiorthyroidarterywhich wasnotedtoappeartobeafork-likedistributionoverthe superior aspect of both the lobes of the thyroid gland.

Pastresearch defined thefact that the superior thyroid arterywasmorefrequentlypresentascompared tothe inferior thyroidartery. ${ }^{12}$ The samestudy described that the presenceand the variability of the superior thyroid arterymaybeinfluencedbytheanthropologicalfactors. ${ }_{12}$ Perhaps studies in a larger group of population may providemuchusefulresults.Researchershaveopinedthat thesuperiorthyroidarteryisaconstantvesselwhereasthe inferiorthyroidarterydoesnotexistinmanymammals. ${ }^{13}$ But our findings proved the contrary.

Variations of the thyroid arteries deserve a special mentioninanatomical,radiologicalandsurgicalstudies. The absence of any artery supplying the thyroid gland maybeaboontoanysurgeonwhohas many problems incombatingthebloodlossduringanythyroidsurgery. Surgeonsmaybeunexpectedlyexposedtothevagaries ofthevascularsystemandprioranatomicalknowledge maybebeneficial.Aprofoundanatomicalinsightintothe variations ofvesselsinthisregionisimportantincorrect interpretationsofangiographicstudiesandincarryingout necksurgeriesincludingdissections, thyroidresections and tracheostomies. ${ }^{14,15}$

\section{CONCLUSION}

A description of arterial variations, especially if they are of rare occurrence, is important for the reporting ofangiographicproceduresandothermodernimaging studies.Inaddition,alldiagnosticandsurgicalinterventions intheneckregionrequireacautiousapproachonaccount ofthepossibilityofarterialvariationsinthisvital region.

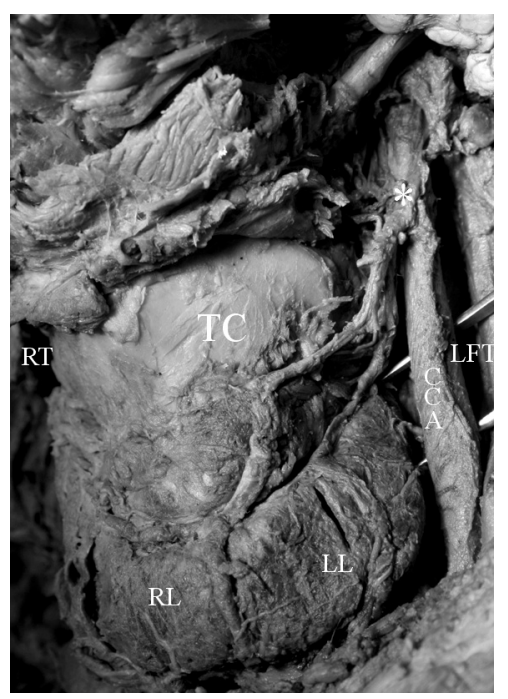

LL - Left lobe of thyroid gland

RL - Right lobe of thyroid gland CCA - Common carotid artery TC - Thyroid cartilage

Figure 1. Dissection of the neck region of an adult male cadaver showing absence of right superior thyroid artery, anomalous origin and distribution of left superior thyroid artery 


\section{REFERENCES}

1. BlumE.Abnormerverlaufeinerunterenschilddrusenarterie. Werner Klin Wschr 1962;74:239-40.

2. Braine, J, Funck-Brentano, P. Les variations des arteres du corpsthyroide.Etuded'anatomiechirurgicale.AnnAnatPathol 1934;11:125-55.

3. Krudy AG, Doppman JL, Brennan MF. Significance of thyroidea imaarteryinarteriographiclocalization of parathyroidadenomas. Radiology 1980;136:51-5.

4. SmithSD,BentonRS.Arareoriginofsuperiorthyroidartery.Acta Anat 1978;101:91-3.

5. YilmazE,CelikHH,DurgunB,AtaseverA, IlgiS.Arteriathyroidea imaarisingfrombrachiocephalictrunkwithbilateralabsenceof inferior thyroid arteries: A case report. Surg Radiol Anat 1993; $15: 197-9$.

6. LiviniF.Studiomorfoloticodellarterietirordee.Sperimentale1900; 54:42-129.

7. StreckeisenA,Beitrage.Zurmorphologyderschilddruse.Virchow Arch, Abteilung A 1886;103:131-86.

8. DaeslerEH,AnsonBJ,ThesurgicalanatomyofSubclavianartery and its branches. Surg Gyne Obstet 1959;108:149-74.
9. Morrigyl B, Sturm W, Absence of three regular thyroid arteries replaced byanunusuallowestthyroidartery:Acasereport.Surg Radiol Anat 1996;18:147-50.

10. GoppertE.,Variabilitatimembryonalen.Artriensystem.VerAnat Ges 1908;32:92-103.

11. HammerDL,MeisAM.Thyroidarteriesandanomaloussubclavian arteryintheWhiteandNegro.AmJPhysAnthropol 1941;28:22736.

12. Toni R, Casa CD, Castorina S, Roti E, Ceda G, Valenti GA. Metaanalysis of inferior thyroid artery variations in different human ethnic groups and their clinical implications. Ann Anat 2005; 18:371-85.

13. WeigleinAH.Ararevariantofthyroidglandvascularization.Surg Radiol Anat 1996;18:233-5.

14. Hollingshead WH., Anatomy for surgeons, Voll. The head and neck, 3rd edi. Philadelphia:Harper \& Row;1982.

15. Lasjaunias P, Berenstein A. Surgical neuroangiography, Vol I. Berlin:Springer Verlag;1987.p.207-19. 